\title{
The dilemma of where to nest: influence of spring snow cover, food proximity and predator abundance on reproductive success of an arctic-breeding migratory herbivore is dependent on nesting habitat choice
}

\author{
Helen B. Anderson • Jesper Madsen • \\ Eva Fuglei · Gitte H. Jensen · Sarah J. Woodin • \\ René van der Wal
}

Received: 24 January 2014/Revised: 29 August 2014/ Accepted: 1 September 2014

(c) Springer-Verlag Berlin Heidelberg 2014

\begin{abstract}
Pink-footed geese Anser brachyrhynchus nest in two contrasting but commonly found habitats: steep cliffs and open tundra slopes. In Svalbard, we compared nest densities and nesting success in these two environments over ten breeding seasons to assess the impact of spring snow cover, food availability to nesting adults and arctic fox Vulpes lagopus (main terrestrial predator) abundance. In years with extensive spring snow cover, fewer geese at both colonies attempted to breed, possibly because snow cover limited pre-nesting feeding opportunities, leaving adults in poor breeding condition. Nesting success at the steep cliff colony was lower with extensive spring snow cover; such conditions force birds to commit to repeated and prolonged recess periods at far distant
\end{abstract}

Electronic supplementary material The online version of this article (doi:10.1007/s00300-014-1574-y) contains supplementary material, which is available to authorized users.

H. B. Anderson $(\bowtie) \cdot$ S. J. Woodin · R. van der Wal

School of Biological Sciences, University of Aberdeen,

Aberdeen AB24 3UU, UK

e-mail: helen.anderson@abdn.ac.uk

S. J. Woodin

e-mail: s.woodin@abdn.ac.uk

R. van der Wal

e-mail: r.vanderwal@abdn.ac.uk

J. Madsen - G. H. Jensen

Department of Bioscience - Kalø, Aarhus University, Grenåvej

14, 8410 Rønde, Denmark

e-mail: jm@dmu.dk

G. H. Jensen

e-mail: ghje@dmu.dk

E. Fuglei

Norwegian Polar Institute, Fram Centre, 9296 Tromsø, Norway

e-mail: eva.fuglei@npolar.no feeding areas, leaving nests open to predation. By contrast, nesting success at the open tundra slope was not affected by spring snow cover; even if birds were apparently in poor condition they could feed immediately adjacent to their nests and defend them from predators. Foxes were the main nest predator in the open tundra slopes but avian predators likely had a larger impact at the steep cliffs colony. Thus, the relative inaccessibility of the cliffs habitat may bring protection from foxes but also deprives geese from readily accessing feeding areas, with the best prospects for successful nesting in low spring snow cover years. Our findings indicate that spring snow cover, predator abundance and food proximity did not uniformly influence nesting success of this herbivore, and their effects were dependent on nesting habitat choice.

Keywords Pink-footed geese $\cdot$ Habitat $\cdot$ Nesting success · Predation $\cdot$ Snow

\section{Introduction}

Habitat type is a major determinant of reproductive success (Heppleston 1972). The factors behind differences in reproductive success between habitat types may be associated with food availability (Gunnarsson et al. 2005) and/ or predator abundance (Madsen et al. 1998). In highly seasonal landscapes, such as the Arctic where the breeding season is substantially constrained by the short summer (Klaassen et al. 2006), weather conditions are also known to have significant impacts on the reproductive effort and success of species (Meltofte et al. 2008). For many bird species, nest initiation may be advanced, delayed or curtailed entirely, dependent on the extent of spring snow cover (Meltofte et al. 2007). Spring snow cover can also 
affect feeding opportunities for herbivorous species such as geese prior to nesting (Prop and De Vries 1993) because late spring snowmelt limits access to preferred habitats that contain abundant edible material (Anderson et al. 2012). The nutrient reserves of breeding female geese are usually just sufficient to enable successful incubation but are severely depleted during egg laying and incubation (Raveling 1979). When feeding opportunities prior to nesting have been poor, incubating geese with substantially depleted fat reserves can experience starvation before the eggs have hatched (Ankney and MacInnes 1978). The proximity of feeding areas to nesting sites could then become critical as recess periods during incubation grow increasingly important to enable adults to feed (Madsen et al. 1998). Such recess periods, however, leave nests open to predation (Inglis 1977; Madsen et al. 2007), with predators then potentially exerting an increased impact on nesting success.

The Svalbard pink-footed goose Anser brachyrhynchus commonly nests in two very different environments, steepsided cliffs and open tundra shallow slopes (Løvenskiold 1964; Nyholm 1965; Wisz et al. 2008). However, a comparison of reproductive effort between these contrasting habitats has not been made (see Frafjord 1993; Madsen et al. 2007). Therefore, here we aim to contrast Svalbard pink-footed goose nest establishment and success in a steep-sided cliff colony and an open tundra slope colony. A 4-year study by Madsen et al. (2007) suggested that late spring snowmelt had a negative impact on the reproductive success of this species, but the study did not consider other major factors which might affect goose nesting success in addition to timing of spring snowmelt, namely predator abundance and food availability (Ankney and MacInnes 1978; Madsen et al. 1992; Eide et al. 2005). Thus, our intention was to understand whether the extent of snow cover at the onset of the breeding season, local abundance of the main terrestrial predator on Svalbard, the arctic fox Vulpes lagopus (Fuglei 2006), and food availability affected the nest establishment and nesting success of pinkfooted geese breeding in two contrasting but commonly found colony types in Svalbard to different extents. In doing so, we aim to demonstrate differences in reproductive effort and nesting success of pink-footed geese at the individual colony scale that may have remained undetected by previous investigations carried out at the regional scale.

\section{Materials and methods}

Study area and study population

The two contrasting colony types in which pink-footed geese in Svalbard nest (steep cliffs and open tundra slopes) are found in close proximity to each other in Sassendalen $\left(78.5^{\circ} \mathrm{N}, 17^{\circ} \mathrm{E}\right)$, one of the main pink-footed goose breeding areas in Svalbard (Jepsen et al. 2002). Sassendalen is approximately $4 \mathrm{~km}$ wide and is a typical broad U-shaped, formerly glaciated valley, containing a central, wide braided river system and open tundra dominated by marsh, ridge and heath vegetation. The cliff colony at Nøisdalen (Figs. 1, 2a), hereafter referred to as 'Cliffs', extends to an area of $0.19 \mathrm{~km}^{2}$ on the sheltered sides of the south facing steep cliffs of this narrow river valley. The open tundra colony at Gåseflatene (Figs. 1, 2b), hereafter referred to as 'Slopes', covers an area of $0.76 \mathrm{~km}^{2}$ and is located on the exposed south-west facing tundra valley slopes of the main Sassendalen valley.

During the short pre-breeding period on Svalbard (from mid- to late May), pink-footed geese spend time at locations (pre-breeding staging sites) which experience earlier spring snowmelt, due to the warming effects of a branch of the North Atlantic Current, than the more easterly inner fjord breeding sites (Glahder et al. 2006; Piechura and Walczowski 2009). While feeding at these pre-breeding staging sites, they replenish body reserves (lost during migration) prior to nesting (Fox et al. 2006; Glahder et al. 2006), thereby enhancing the likelihood of reproductive success (Arzel et al. 2006). Towards the end of May, geese move from pre-breeding sites to their nesting colonies and initiate nesting as soon as snowmelt allows access to nest sites (Madsen et al. 2007). Only the female incubates for 26-27 days, while the male remains close to the nest (Løvenskiold 1964; Inglis 1977). When both adults are present, they are generally able to guard the nest against arctic foxes and avian predators, such as glaucous gulls Larus hyperboreus and arctic skuas Stercorarius parasiticus (Inglis 1977, Madsen et al. 2007). However, if the female goose leaves the nest, the male follows her (Løvenskiold 1964; Nyholm 1965; Inglis 1977), leaving the eggs exposed to potential predation (Sigurdsson 1974; Madsen et al. 2007). Recess periods are required during incubation when the stored fat reserves of female geese become depleted with time (Ankney and MacInnes 1978; Spaans et al. 1999, 2007). Arctic foxes are also capable of attacking and killing geese (Prestrud 1992), particularly solitary incubating geese (Inglis 1977; Frafjord 1990), which may occur if the male moves too far away from the nest to feed.

\section{Reproductive parameters}

To determine the number of occupied nests, nest density and the nesting success of pink-footed geese, systematic searches for nests were undertaken for 10 years (2003-2007 and 2010-2014; due to funding constraints, no expeditions were undertaken in 2008 and 2009). Hence, we 
Fig. 1 False colour aerial photograph (subset of aerial image S2009 13824 0049, Norwegian Polar Institute) of north-eastern Sassendalen, Svalbard, with the areas covered by the pink-footed goose $A$. brachyrhynchus Cliffs colony at Nøisdalen and open tundra Slopes colony at Gåseflatene outlined. Vegetated areas are coloured red, with arrows from the Cliffs colony indicating locations of the nearest suitable goose foraging areas. For the Slopes colony, foraging areas are within and immediately adjacent to nest sites. The small inset map shows Svalbard with the location of the study area in black

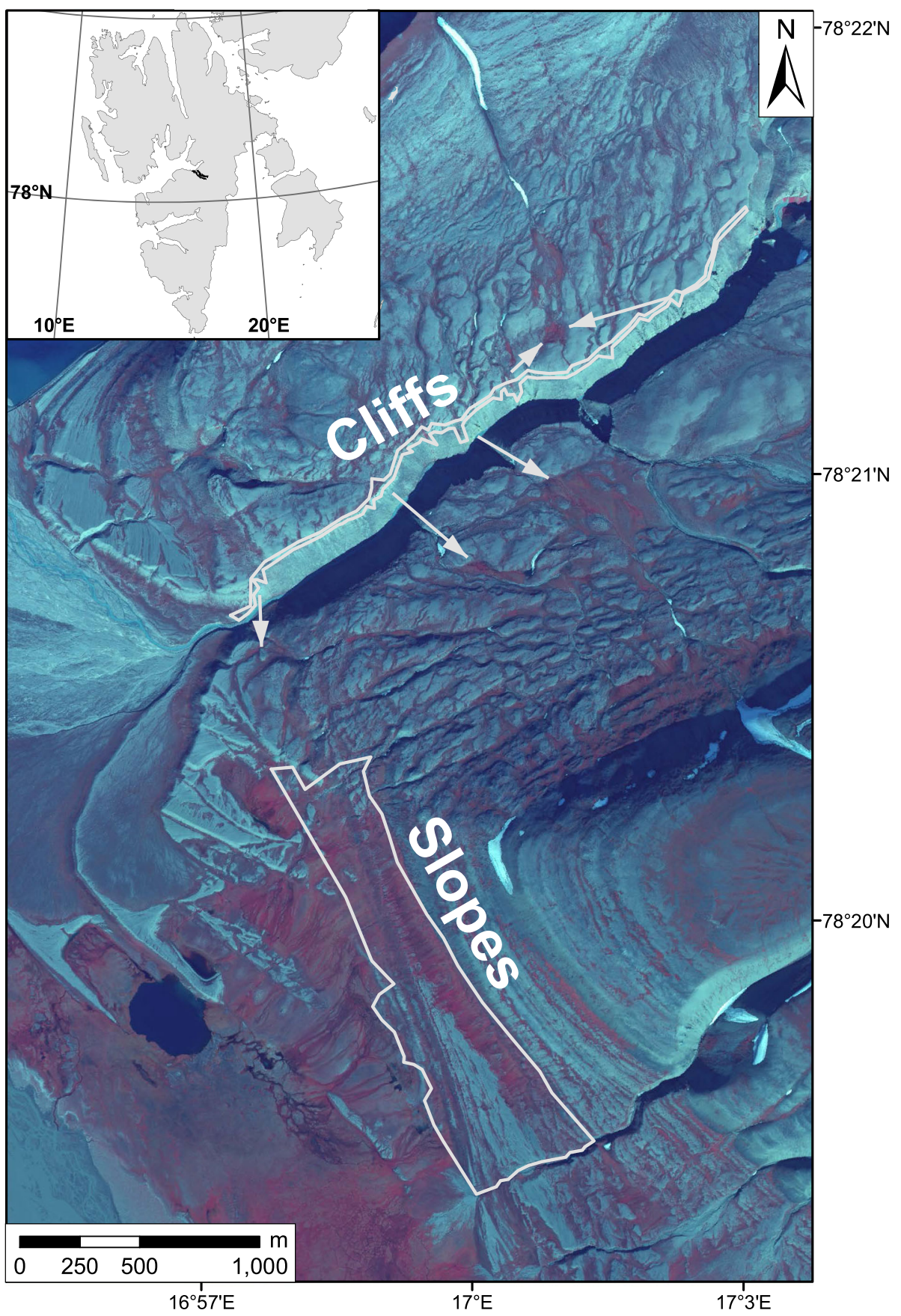

present data on nest density and nesting success at two sites (Cliffs and Slopes) for 10 years.

We determined nesting success after hatching rather than regular checking of each individual nest during the incubation period because the pink-footed goose is particularly shy of humans (Madsen et al. 2009). Previous work in the same area showed that when nests were approached by humans, both the male and female goose were frightened off the nest. This left the nest unattended and subject to an increased predation rate of $35 \%$, with both glaucous gulls and skuas following humans as they entered the colony (Madsen et al. 2009). We judged this level of disturbance to be unacceptably high and therefore inspected the nests as soon as possible after hatching to avoid disturbing incubating geese and causing nest failures. Searches were conducted over the same fixed areas (see Fig. 1 for colony boundaries), which allowed nest density in a colony to be calculated and between-year comparisons in nest densities to be made. We systematically searched for nests by working in pairs and walking straight line 
transects (spaced at 5-m intervals) across the tundra slopes, along the cliff edge and at right angles from the cliff edge down the steep slopes towards the river. The coordinates of every nest found were recorded, stored in a handheld GPS (Garmin GPS60), and each nest was labelled with a unique number written on a stone and placed unobtrusively next to the nest. Checking the id number of a nest and its coordinates with that of nests identified in previous survey years allowed us to determine how many known nests had been missed in any 1 year. This resulted in a detection probability of $94 \%$ (211 out of 226) in the Slopes colony and $98 \%$ (53 out of 54) in the Cliffs colony in 2011, and $93 \%$ in the Slopes (236 out of 254) and $100 \%$ in the Cliffs in 2012. These detection rates compare favourably with those proposed by Johnson and Shaffer (1990) for colonial breeding species. Hence, this approach is unlikely to have influenced the outcomes of our research.

Nests were identified as having been used during the current breeding season if fresh down feathers were found within the nest bowl and fresh droppings were present in the nest vicinity. Nest bowls which contained no down, or where the down feathers were obviously old and very well weathered, were regarded as not having been used during that current season. Empty nests, nests containing eggshells with no membranes and eggs with clear indications of gull peck marks or fox tooth marks on eggs, were recorded as having been abandoned/predated. Successful nests were those where membranes were still present within the eggshell remains (Davis et al. 1998; Madsen et al. 2007; Prop et al. 2013). A small number of nests, for which a nest bowl lacked eggshell remains and contained down which had been moderately weathered, were labelled as predated when they may have been unused. However, this concerned only 14 out of 226 nests in the year with the most nests (i.e. 2010) and thus will not have significantly influenced our results. Nesting success (at the colony level) was calculated as the proportion of successful nests (as defined above).

Snow cover

Cloud-free MODIS satellite images (spectral bands 1 $(620-670 \mathrm{~nm})$ and $2(841-876 \mathrm{~nm})$, resolution $250 \mathrm{~m})$ were used to determine snow cover in the Sassendalen area during late May (the beginning of the nesting period for pink-footed geese; Madsen et al. 2007) for the same 10 years (2003-2007 and 2010-2014) for which we had pink-footed goose nest information. It proved impossible to obtain cloud-free images for exactly the same date in each year, hence images used for analysis dated from 21 to 31 May. No atmospheric correction was applied and the MODIS Swath Reprojection Tool (https://lpdaac.usgs.gov/tools/modis_reprojection_tool_ swath) was used to geo-reference each image. Snow cover estimates for each image were completed in accordance with
Madsen et al. (2007) by using visual training points and a maximum likelihood classification to generate a two class (snow, no snow) standard confusion matrix, with no less than 50 points identified for each class. Time series oblique photographs of snow coverage in 2003 and 2004 over the 21-31 May period suggested limited snowmelt between image acquisition dates, and we did not find any correlation between the date of image capture (day of year) and snow cover estimate $(r=0.08, n=10, p=0.83)$. Snowmelt coincides with temperatures above freezing (Semmens et al. 2013), and we found a negative correlation between the number of days in May when the temperature was above freezing (data recorded at Svalbard airport, approximately $37 \mathrm{~km}$ west of the study area; available from the Norwegian Meteorological Institute) and our snow cover estimates $(r=-0.90, n=10$, $p<0.001$; Table 1). Hence, we have assumed that the prevailing low temperatures (at or below freezing) and minimal precipitation (see Online Resource 1) in the days prior to and after image acquisition caused marginal error in our estimates of annual snow cover and that the images were representative of snow conditions at the same date from year to year and are therefore comparable.

\section{Forage availability}

To determine how far female geese in each colony had to travel from their nest to find food, the distance from each individual nest to the nearest patch of suitable goose forage vegetation (see below), in any direction, was measured using a range finder (Nikon Forestry 550, range 10-500 m) in 2010, 2011 and 2012. The distances from all nests within a colony were summed to derive a mean distance to forage for geese within a colony. As the distances to forage for each year were not significantly different $(p>0.5)$, we pooled the data to give an overall mean distance to forage for each colony. Potential feeding areas (minimum size limit set was $2 \mathrm{~m} \times 2 \mathrm{~m}$ and the median patch size was $15,000 \mathrm{~m}^{2}$ ) included patches that were both hidden and visible from each nest. Feeding areas were wet marshes with standing water and contained the vascular plants Dupontia spp., Carex spp., Eriophorum scheuchzeri, Equisetum arvense and Bistorta vivipara, with the ground coverage dominated by moss species. Use of foraging patches by pink-footed geese was confirmed by checking for the presence of fresh goose droppings and/or new grubbing holes/disruptions to the moss mat (Speed et al. 2009) within the patch of vegetation and by visual observations of feeding geese during the nesting period.

Local arctic fox abundance

Since we expected nest predation rates to increase with an increasing number of arctic foxes, we measured the 
Table 1 Acquisition dates, derived snow cover estimates, obtained from MODIS satellite imagery taken of the Sassendalen area of Svalbard and the number of days in May when the temperature is above $0{ }^{\circ} \mathrm{C}$ (Svalbard airport) for each of the study years

\begin{tabular}{lllllllllll}
\hline & 2003 & 2004 & 2005 & 2006 & 2007 & 2010 & 2011 & 2012 & 2013 & 2014 \\
\hline Image acquisition date & 25 May & 28 May & 31 May & 31 May & 25 May & 25 May & 25 May & 21 May & 26 May & 25 May \\
Snow cover estimate & $77 \%$ & $64 \%$ & $82 \%$ & $51 \%$ & $55 \%$ & $45 \%$ & $79 \%$ & $83 \%$ & $70 \%$ & $75 \%$ \\
May days above $0{ }^{\circ} \mathrm{C}$ & 8 & 13 & 9 & 20 & 13 & 22 & 11 & 5 & 9 \\
\hline
\end{tabular}

abundance of foxes in the immediate vicinity of each colony for the same 10 years in which we recorded pinkfooted goose nest data (2003-2007 and 2010-2014). Local abundance was determined as the combined total of adult arctic fox and pup numbers from dens situated near or within each of the colonies separately (four dens in the Cliffs area, two dens in the Slopes area). Surveys of already known fox den sites within the study area (Eide et al. 2012) were conducted annually between 28 June and 28 July by visiting each den to obtain data on litter size. Minimum litter size was determined from the number of pups seen when parents and pups were observed together at the den site. The maximum distance from the centre of a colony to the furthest den was $3 \mathrm{~km}$ at both the Cliffs and Slopes colonies, well within the home range sizes recorded for arctic foxes during spring in these habitat types (Eide et al. 2004). Natal dens were not necessarily used every year, hence local fox abundance in some years was zero.

Statistical analysis

All statistical analyses were carried out using R v3.0.1 (R Development Core Team 2013). Pearson's correlation coefficients were calculated to determine statistical significance of possible relationships between spring snow cover and (1) year, (2) day of year and (3) the number of days in May when the temperature was above freezing (Svalbard airport). Generalised linear models (GLMs) with a negative binomial distribution and a log link function were used to test for interactions between nest density and (1) colony type, (2) year and (3) snow cover. Where interactions were significant, we then used a similar model structure to test the relationships between nest density and year or snow for each individual colony type. We included period as a factor (two levels: 2003-2007 and 2010-2014) when analysing the relationship between snow cover and nest density at the Slopes colony because the large number of young produced in 2006 and 2007 and very low spring snow cover in 2010 (45\%) made many potential nest sites on the open tundra slope available, thereby allowing a much larger number of geese to nest in 2010 than had been observed in previous years. To determine whether there were any differences in nesting success between colony types, we fitted GLMs with a quasi-binomial distribution and a logit link function. Interactions between nesting success and (1) colony type, (2) year, (3) snow cover and (4) local fox abundance were tested. Where interactions were significant, we then used a similar model structure to test the relationships between nesting success and year, snow cover and fox abundance for each individual colony type. When analysing both nest density and nesting success, we started with the full model and used a stepwise procedure, based on test-statistics and $p$ values, to eliminate non-significant terms.

When analysing how far geese had to travel to find suitable feeding areas, based on distances from nests in each colony, we used a $t$ test with a specification for unequal variances ( $F$ test for equal variances in the data: $\left.F_{51,221}=22.1, p<0.001\right)$. Results detailing food availability are quoted as mean \pm SE.

\section{Results}

Snow cover

Snow cover during late May in the study area varied considerably over the 10 year study period (Table 1 ). The lowest extent of snow cover (45\%) was recorded in 2010, while the greatest extent was in $2012(83 \%)$. There was no evidence of any directional change in the extent of spring snow cover over the years $(r=0.15, n=10, p=0.67)$.

Pink-footed goose nest densities

Nest density at the Slopes colony increased substantially over the years in which the study was conducted $(z=6.25$, $p<0.001$; Fig. 2d), but nest densities did not change significantly at the Cliffs colony (Fig. 2c) (colony type $x$ year $z=5.92, p<0.001)$. Extensive snow cover appeared to suppress the numbers of birds nesting $(z=-3.42$, $p<0.001$; Fig. 2e, f), thereby influencing the numbers (and hence nest density) in both habitats to a similar extent (as can be judged from the non-significant colony type $\mathrm{x}$ snow cover interaction $z=0.70, p=0.49$ ).

Pink-footed goose nesting success

Annual nesting success was variable at both colonies; a low of $4 \%$ in 2005 and a high of $67 \%$ in 2010 were observed at the Cliffs colony, while at the Slopes colony, nesting success 
Fig. 2 The Cliffs (a) and Slopes (b) nesting environments, pink-footed goose A. brachyrhynchus nest densities and numbers of occupied nests across the years (c, d) and in relation to the extent of spring snow cover (e, f) at a Cliffs colony and open tundra Slopes colony in Sassendalen, Svalbard, respectively. Data for the Slopes colony are split into two different categories reflecting the large differences in nest numbers in that colony during the study period, with black symbols representing data from 2003 to 2007 and open symbols data from 2010 to 2014. Fitted lines from the GLM analyses are shown in $(\mathbf{e}, \mathbf{f})$ (a) Cliffs



(b) Slopes

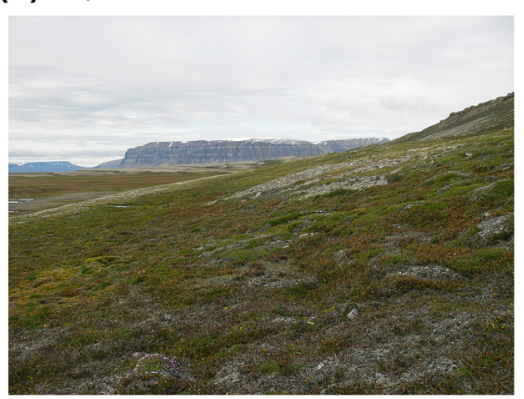

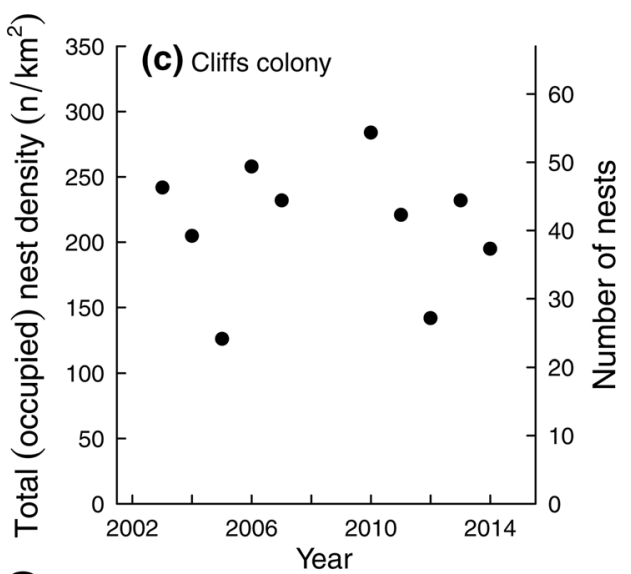

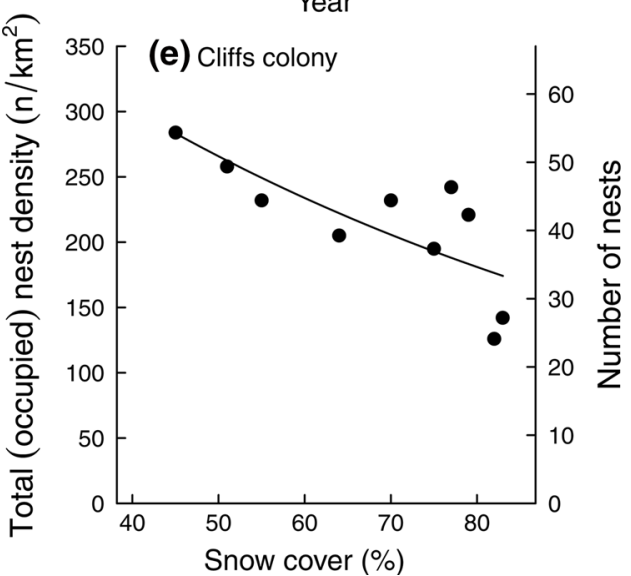



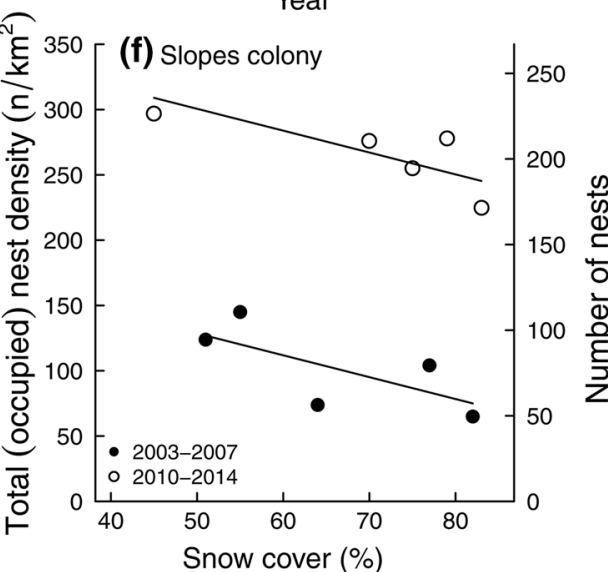

was generally higher $\left(t_{13}=3.80, p=0.001\right)$ and ranged between $34 \%$ (2003) and $75 \%$ (2012). Nesting success at both colonies almost doubled over the 10-year study period $\left(t_{13}=2.38, p=0.03\right.$; Fig. 3a, b). Extensive spring snow cover appeared to suppress nesting success of Cliff breeding birds ( $t_{8}=2.50, p=0.04$; Fig. 3c) but not those nesting at the Slopes (Fig. 3d) (colony type $\times$ snow cover $t_{13}=2.24$, $p=0.04)$. The reverse was found for fox abundance, with evidence for a suppressive effect in the Slopes colony $\left(t_{8}=2.29, p=0.05\right.$; Fig. 3f) but no demonstrable effect on nesting success at the Cliffs (Fig. 3e) (colony type $\times$ local fox abundance $t_{13}=2.16, p=0.05$ ).
Food availability

A major difference between the two colonies was the distance adult birds had to travel to find food, with Cliffs nesting geese travelling on average ten times further $(338 \pm 32 \mathrm{~m})$ than Slopes nesting birds $(32 \pm 3 \mathrm{~m}$, $t_{52}=9.71, p<0.001$; Fig. 1). Most of the feeding areas closest to Cliff nesting birds were on the opposite side of the river valley (Fig. 1), necessitating the need to fly to these areas. This is in stark contrast to Slopes nesting birds that could easily walk the short distances from the nest to feeding patches (Fig. 1). 
Fig. 3 Pink-footed goose $A$. brachyrhynchus nesting success across the years $(\mathbf{a}, \mathbf{b})$, in relation to the extent of spring snow cover $(\mathbf{c}, \mathbf{d})$ and in relation to local arctic fox (V. lagopus) abundance $(\mathbf{e}, \mathbf{f})$ at a Cliffs colony and open tundra Slopes colony in Sassendalen,

Svalbard, respectively. Data at the Slopes colony are split into two different categories reflecting the large differences in nest numbers in that colony during the study period, with black symbols representing the data from 2003 to 2007 and open symbols from 2010 to 2014. Fitted lines from the GLM analyses are shown in (a, b, c, f)
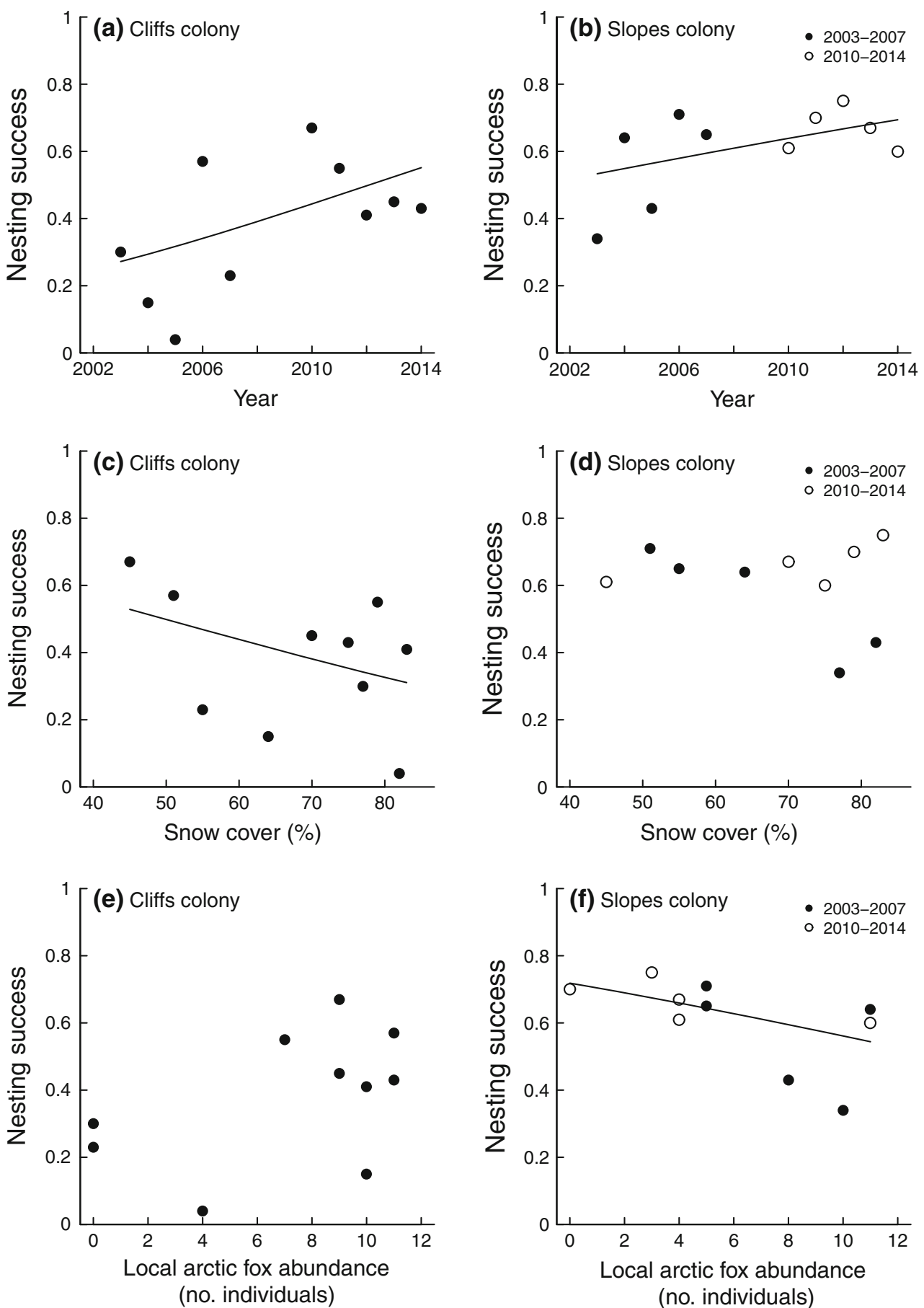

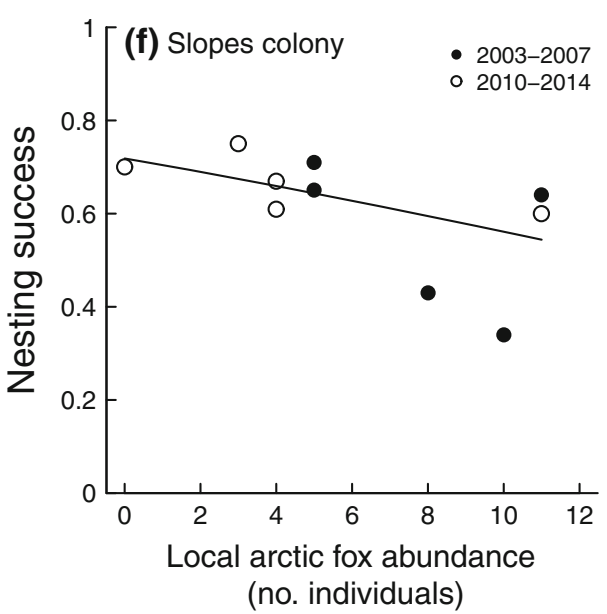

\section{Discussion}

This study, conducted over ten breeding seasons, has concentrated on the main factors previously shown to have influenced goose nest establishment and success, i.e. snow cover, predation and food availability (Ankney and MacInnes 1978; Madsen et al. 1992; Eide et al. 2005; Madsen et al. 2007). In doing so, we can outline the key differences in the reproductive effort and nesting success of pink-footed geese which nest in starkly different environments. The impact of high spring snow cover on the nest establishment of pinkfooted geese was universally negative. Effects on subsequent nesting success, however, differed between the two colonies studied, with high fox abundance being a constraint in open tundra (Slopes colony) and late snowmelt suppressing nesting success at the Cliffs. The relative inaccessibility of the latter habitat may therefore bring protection from foxes but also deprives the geese from readily accessing suitable feeding areas, leading to high nesting success only being achievable in years with low spring snow cover. 
Extensive spring snow cover can prolong the prebreeding period and limit feeding opportunities (Prop and De Vries 1993; Anderson et al. 2012). The powerful negative influence that extensive spring snow cover had on nest establishment, regardless of nesting environment, is likely a reflection of the importance of the pre-breeding period to geese for feeding and improving body condition prior to nesting. When spring snow cover was extensive, nest establishment was reduced at both the Slopes and Cliffs colony because many geese did not attempt to breed, presumably due to their poor breeding condition. Additionally, extensive snow cover may also physically restrict access to nest sites. For instance, at the Cliffs, vegetated patches suitable for nest establishment were few and far between. Hence, the potential to establish a nest elsewhere in the Cliffs area is severely limited by lack of suitable nesting habitat. This is supported by the absence of any trend in nest density at the Cliffs over the 10-year study period. At the Slopes, an increase in nest density over the study period suggests that the availability of potential nesting sites was considerably less restricted. Such differences in nest densities between colony types may suggest that the Cliffs environment was initially preferred and the Slopes habitat has been under-utilised. We therefore hypothesise that the Cliffs were occupied first and a combination of reaching the maximum nest density possible in this habitat and an increasing population size has resulted in greater numbers of geese breeding in the open tundra Slopes environment thereafter.

Food proximity is likely the key to observed differences between colonies in the responses of nesting success to changing snow cover conditions. When spring snow cover was extensive, it had a particularly negative carry-over effect on the geese nesting in the Cliffs colony. Here, geese are unable to nest close to food patches, and therefore must move far away from the nest to feed. Birds in poorer condition with heavily depleted fat reserves due to late spring snowmelt likely require longer/more frequent nest recesses (Prop and De Vries 1993), thus leaving the eggs open to a greater risk of predation. At this location, arctic foxes seem to prefer a diet of nearby nesting seabirds, e.g. fulmar Fulmarus glacialis, Brünnich's guillemot Uria lomvia and little auk Alle alle (Jepsen et al. 2002, Eide et al. 2005). Thus, we suspect that avian predators were the cause of reduced nesting success at the Cliffs colony, although further studies would be required to prove this. The situation at the Slopes colony is somewhat different. The close proximity of feeding patches to nests means that even if geese are in poor breeding condition with low fat reserves due to late spring snowmelt, they can easily feed during incubation and quickly return to defend the nest if predators are spotted. Arctic foxes have a strong negative impact on nesting success at the Slopes colony, indicating their preference for goose eggs at this location (Jepsen et al.
2002; Eide et al. 2005). This large impact of arctic foxes at the Slopes may mask any carry-over effect of extensive spring snow cover on nesting success in this habitat. The lower overall nesting success at the Cliffs colony compared to the Slopes may be due to the long distances and often interrupted view between feeding areas and nests at the Cliffs. This likely means that while Cliff nesting adults are feeding, they are often unable to observe predators approaching the nest and in many cases are unable to return to defend it.

If nesting in the Slopes habitat offers the reproductive benefits of nearby food and higher nesting success, then nesting in the Cliffs habitat where egg losses are greater appears to be counterintuitive. However, geese are longlived with an age-related improvement in reproductive success and there is limited evidence for senescence in older birds (Forslund and Larsson 1992; Black and Owen 1995). Hence, long-term adult (female) survival may be more important than short-term reproductive success. Over the 10-year study, we have never found any goose carcasses at the Cliffs colony but have observed fox-killed geese at the Slopes colony. In 2014 at the Slopes colony, we found at least 20 pink-footed goose carcasses (12 intact and 16 single wings), most of which were within $1 \mathrm{~m}$ of an unsuccessful nest, thus highlighting the vulnerability of open tundra nesting adult geese to predation by arctic foxes. Defence against predation by arctic foxes is thought to be why the smaller barnacle goose Branta leucopsis nests in inaccessible habitats such as islands and cliffs (Løvenskiold 1964), except for years when arctic fox presence is extremely low (Tombre et al. 1998). The risk of injury or death to nesting female lesser snow geese from arctic fox attacks was considerably greater than the risk to males (Samelius and Alisauskas 2006). Therefore, defence against adult (female) predation by arctic foxes, the main terrestrial predator on Svalbard (Fuglei 2006), may underpin why some pink-footed geese nest in relatively secure and defendable cliff habitat rather than on the open tundra (see Frafjord 1990). Indeed, the importance of longterm adult survival over short-term reproductive success may also explain why male pink-footed geese follow their mates if they leave the nest (Løvenskiold 1964; Nyholm 1965; Inglis 1977), thereby investing in her protection and survival but leaving the nest/eggs undefended.

In those years when spring snow cover is high, fewer geese attempt to breed (Madsen et al. 2007 and this study). Limited feeding opportunities prior to nesting can lead to breeding birds in poor condition (Prop and De Vries 1993) and facing the prospect of running out of energy towards the end of the incubation period. It is in the Cliffs environment, where food resources are poor, that the interplay between spring snow cover and nest predation risk is fully acted out, as witnessed in the negative relationship 
observed between nesting success and spring snow cover. However, establishing a nest in a relatively inaccessible (to arctic foxes) location such as the Cliffs may be a more effective strategy for long-term adult survival than nesting in an area like the Slopes, which appears less secure but offers the immediate rewards of adjacent food resources. The Cliffs area appears to have reached and maintained maximum capacity for some time; therefore, opportunities for establishing a nest there are limited. Geese seem now restricted to nesting in the much more abundant open tundra Slopes area, where their eggs are at greater risk of arctic fox predation, but adults benefit from the close proximity of food resources. These findings highlight that previous investigations into pink-footed goose reproductive success, conducted only at a larger spatial scale, have overlooked the very stark differences that occur between different nesting environments. Although a much larger number of years would likely be required to identify whether any possible additional, and less influential, factors also play a role in nest establishment and nesting success, the impacts of spring snow cover, food proximity and predator abundance appear to substantially depend on choice of nesting habitat by individual pink-footed geese.

Acknowledgments We thank Juliet Blum, Malcolm Parsons and Troels Hastrup for contributions to data collection in the field. We are indebted to Christiaane Hübner for her considerable help before, during and after fieldwork. Norwegian Polar Institute supplied vital logistic support and the Governor of Svalbard allowed access to Sassendalen. Part of this work was undertaken, while HBA was in receipt of a studentship from the College of Life Science and Medicine, University of Aberdeen.

\section{References}

Anderson HB, Godfrey TG, Woodin SJ, Van der Wal R (2012) Finding food in a highly seasonal landscape: where and how pink-footed geese Anser brachyrhynchus feed during the Arctic spring. J Avian Biol 43:415-422

Ankney CD, MacInnes CD (1978) Nutrient reserves and reproductive performance of female lesser snow geese. Auk 95:459-471

Arzel C, Elmberg J, Guillemain M (2006) Ecology of springmigrating Anatidae: a review. J Ornithol 147:167-184

Black JM, Owen M (1995) Reproductive performance and assortative pairing in relation to age in barnacle geese. $\mathrm{J}$ Anim Ecol 64:234-244

Davis JB, Kaminski RM, Stephens SE (1998) Wood duck eggshell membranes predict duckling numbers. Wildl Soc B 26:299-301

Eide NE, Jepsen JU, Prestrud P (2004) Spatial organization of reproductive Arctic foxes Alopex lagopus: responses to changes in spatial and temporal availability of prey. J Anim Ecol 73:1056-1068

Eide NE, Eid PM, Prestrud P, Swenson JE (2005) Dietary responses of arctic foxes Alopex lagopus to changing prey availability across and Arctic landscape. Wildl Biol 11:109-121

Eide NE, Stein A, Prestrud P, Yoccoz NG, Fuglei E (2012) Reproductive responses to spatial and temporal prey availability in a coastal Arctic fox population. J Anim Ecol 81:640-648
Forslund P, Larsson K (1992) Age-related reproductive success in the barnacle goose. J Anim Ecol 61:195-204

Fox AD, Francis IS, Bergersen E (2006) Diet and habitat use of Svalbard pink-footed geese Anser brachyrhynchus during arrival and pre-breeding periods in Adventdalen. Ardea 94:691-699

Frafjord K (1990) A study of the pink-footed goose in Gipsdalen, Svalbard, during the pre-breeding and early breeding periods. In: Severinsen T, Hansson R (eds) Environmental Atlas Gipsdalen, Svalbard Vol. III. Reports on the Fauna of Gipsdalen, Norsk Polarintitutt Rapport nr. 66, Norwegian Polar Institute, Olso, pp $1-18$

Frafjord K (1993) The arctic fox as a predator on the Svalbard pinkfooted goose. Fauna 46:10-14

Fuglei E (2006) Arctic fox. In: Kovacs KM, Lydersen C (eds) Birds and mammals of Svalbard. Norsk Polarintitutt, Oslo, pp 77-80

Glahder CM, Fox AD, Hübner CE, Madsen J, Tombre IM (2006) Prenesting site use of satellite transmitter tagged Svalbard Pinkfooted Geese Anser brachyrhynchus. Ardea 94:679-690

Gunnarsson TG, Gill JA, Newton J, Potts PM, Sutherland WJ (2005) Seasonal matching of habitat quality and fitness in a migratory bird. Proc R Soc B 272:2319-2323

Heppleston PB (1972) The comparative breeding ecology of oystercatchers (Haematopus ostralegus L.) in inland and coastal habitats. J Anim Ecol 41:23-51

Inglis IR (1977) The breeding behaviour of the pink-footed goose: behavioural correlates of nesting success. Anim Behav 25:747-764

Jepsen JU, Eide NE, Prestrud P, Jacobsen LB (2002) The importance of prey distribution in habitat use by arctic foxes (Alopex lagopus). Can J Zool 80:418-429

Johnson DH, Shaffer TL (1990) Estimating nest success: when Mayfield wins. Auk 107:595-600

Klaassen M, Abraham KE, Jefferies RL, Vrtiska M (2006) Factors affecting the site of investment, and the reliance on savings for arctic breeders: the capital-income dichotomy revisited. Ardea 94:371-384

Løvenskiold HL (1964) Avifauna Svalbardensis. Nor Polarinst Skr 129:125-134

Madsen J, Bregnballe T, Hastrup A (1992) Impact of the arctic fox Alopex lagopus on nesting success of geese in southeast Svalbard, 1989. Polar Res 11:25-39

Madsen J, Bregnballe T, Frikke J, Kristensen JB (1998) Correlates of predator abundance with snow and ice conditions and their role in determining timing of nesting and breeding success in Svalbard light-bellied brent geese Branta bernicla hrota. In: Mehlum F, Black JM, Madsen J (eds) Research on Arctic Geese. Proceedings of the Svalbard Goose Symposium, Oslo, Norway, 1997. Norsk Polarinstitutt Skr 200, Norsk Polarinstitutt, Oslo, pp 221-234

Madsen J, Tamstorf M, Klaassen M, Eide N, Glahder C, Rigét F, Nyegaard H, Cottaar F (2007) Effects of snow cover on the timing and success of reproduction in high-Arctic pink-footed geese Anser brachyrhynchus. Polar Biol 30:1363-1372

Madsen J, Tombre I, Eide NE (2009) Effects of disturbance on geese in Svalbard: implications for regulating increasing tourism. Polar Res 28:376-389

Meltofte H, Piersma T, Boyd H, McCaffery B, Ganter B, Golovnyuk VV, Graham K, Gratto-Trevor CL, Morrison RIG, Nol E, Rösner HU, Schamel D, Schekkerman H, Soloviev MY, Tomkovich PS, Tracey DM, Tulp I, Wennerberg L (2007) Effects of climate variation on the breeding ecology of Arctic shorebirds. Meddelelser om Grønland 59:1-48

Meltofte H, Høye TT, Schmidt NM (2008) Effects of food availability, snow and predation on breeding performance of waders at Zachenberg. Adv Ecol Res 40:325-342

Nyholm ES (1965) Ecological observations on the geese of Spitsbergen. Ann Zool Fenn 2:197-207 
Piechura J, Walczowski W (2009) Warming of the west Spitsbergen current and sea ice north of Svalbard. Oceanologia 51:147-164

Prestrud P (1992) Food habitats and observations of the hunting behaviour of arctic foxes, Alopex lagopus, in Svalbard. Can Field Nat 106:225-236

Prop J, de Vries J (1993) Impact of snow and food conditions on the reproductive performance of barnacle geese (Branta leucopsis). Ornis Scand 24:110-121

Prop J, Oudman T, Van Spanje TM, Wolters EH (2013) Patterns of predation of pink-footed goose nests by polar bear. Ornis Nor 36:38-46

Raveling DG (1979) The annual cycle of body composition of Canada geese with special reference to control of reproduction. Auk 96:234-252

Samelius G, Alisauskas RT (2006) Sex-biased costs in nest defence behaviours by lesser snow geese (Chen caerulescens): consequences of parental roles? Behav Ecol Sociobiol 59:805-810

Semmens KA, Ramage J, Bartsch A, Liston GE (2013) Early snowmelt events: detection, distribution, and significance in a major sub-arctic watershed. Environ Res Lett 8, article no. 014020. doi:10.1088/1748-9326/8/1/014020

Sigurdsson JB (1974) Studies on breeding biology of pink-footed geese (Anser brachyrhynchus). In: Sigurdsson JB, Gardarsson A (eds) Skýrsla um rannsóknir I pjórsárverum 1972. Orkustofnun Raforkudeild, Reykjavik, pp 1.2-1.39

Spaans B, Van der Veer W, Ebbinge BS (1999) Cost of incubation in a greater white-fronted goose. Waterbirds 22:151-155

Spaans B, Van't Hoff CA, Van der Veer W, Ebbinge BS (2007) The significance of female body stores for egg laying and incubation in dark-bellied brent geese Branta bernicla bernicla. Ardea 95:3-15

Speed JDM, Woodin SJ, Tømmervik H, Tamstorf MP, Van der Wal R (2009) Predicting habitat utilization and extent of ecosystem disturbance by an increasing herbivore population. Ecosystems 12:349-359

Tombre IM, Mehlum F, Loonen MJJE (1998) The Kongsfjorden colony of barnacle geese: nest distribution and the use of breeding islands 1980-1997. In: Mehlum F, Black JM, Madsen J (eds) Research on Arctic Geese. Proceedings of the Svalbard Goose Symposium, Oslo, Norway, 1997. Norsk Polarinstitutt Skr 200, Norsk Polarintitutt, Oslo, pp 57-65

Wisz MS, Tamstorf MP, Madsen J, Jespersen M (2008) Where might the western Svalbard tundra be vulnerable to pink-footed goose (Anser brachyrhynchus) population expansion? Divers Distrib 14:26-37 